\title{
Theoretical studies on thermal stability of alkyl-substituted 1,2-dioxetanes
}

\author{
Erick L. Bastos ${ }^{a}$ and Wilhelm J. Baader ${ }^{b}, *$ \\ ${ }^{a}$ Centro de Ciências Naturais e Humanas, Fundação Universidade Federal do ABC. Rua Santa \\ Adélia, 166. 09210-170 Santo André/SP Brazil \\ ${ }^{b}$ Instituto de Química, Universidade de São Paulo. Av. Prof. Lineu Prestes, 748 Bl. 12S. 05508- \\ 900 São Paulo/SP Brazil \\ E-mail: wjbaader@iq.usp.br
}

\section{Dedicated to Prof. Waldemar Adam on the occasion of his $\mathbf{7 0}^{\text {th }}$ birthday}

\begin{abstract}
The geometry of thirty alkyl-substituted 1,2-dioxetanes derivatives was optimized using theoretical methods. It was found that AM1 and PM3 semiempirical methods do not adequately predict dihedral angles of the peroxidic ring of highly stabilized 1,2-dioxetanes. Geometric parameters calculated by $a b$ initio and hybrid DFT methods are in better agreement with experimental activation parameter data than the one obtained by semiempirical calculations. Among those, the B3LYP method with the 6-31G(d) basis set is the most adequate one. Very good correlation between theoretical carbon-carbon bond distances and experimental activation parameters was found for all $a b$ initio and hybrid DFT methods, whereas, oxygen-oxygen bond distances and dihedral angles do not correlate well with the activation parameters. Results obtained by different methods are compared and a qualitative explanation for the stabilization effect of alkyl groups on the 1,2-dioxetane ring is proposed.
\end{abstract}

Keywords: 1,2-Dioxetanes, thermal stability, quantum mechanics.

\section{Introduction}

1,2-Dioxetanes constitute a large class of isolable high-energy molecules whose uncatalyzed thermal decomposition generates electronically excited products in considerable yields. ${ }^{1,2}$ These products are formed preferentially in the electronically excited triplet state and the mechanism of this transformation was extensively studied during the 1970's and mid 1980's. ${ }^{1,3-7}$ As consequence, several hundreds of 1,2-dioxetane derivatives were synthesized. ${ }^{3-6}$ Among them, those originated from hindered olefins have shown remarkable thermal stability. ${ }^{8}$ 
In the late 1980's, spiroadamantane-substituted dioxetanes with a protected phenolate group were first prepared. ${ }^{9-11}$ Since these 'triggerable' 1,2-dioxetanes have a high potential in commercial applications, most prominently in chemiluminescence immunoassays, the 1990's were marked by the synthesis and studies of the chemiluminescence properties of this class of 1,2-dioxetanes. More recently, most of research on the mechanism of excited state formation in thermal cleavage of 1,2-dioxetanes has been carried out by quantum chemical calculations. ${ }^{12-14}$

However, up to now, no definitive explanation for the chemiexcitation mechanism in 1,2dioxetane thermolysis was obtained, neither by experimental nor theoretical means. ${ }^{2,7,13,15}$ Most attempts on mechanistic analysis of this process focused on the question whether the $\mathrm{O}-\mathrm{O}$ and $\mathrm{C}$ $\mathrm{C}$ bond cleavage occurs concertedly or in a stepwise manner. ${ }^{1,12-14,16-18}$ Theoretical evidence reported so far indicates that the $\mathrm{C}-\mathrm{C}$ bond stretches along the reaction coordinate, which is consistent with the intuitively assessed merged dioxetane cleavage mechanism, which predicts the concerted, although not simultaneous, cleavage of the $\mathrm{O}-\mathrm{O}$ and $\mathrm{C}-\mathrm{C}$ bonds, with the elongation of the $\mathrm{O}-\mathrm{O}$ bond being more advanced than that of the $\mathrm{C}-\mathrm{C}$-bond (concerted biradicallike mechanism). ${ }^{19,20}$

This mechanism was first proposed by Adam and used to rationalize both thermal stability and singlet/triplet quantum yields in the series of methyl-substituted 1,2-dioxetanes, including the parent 1,2-dioxetane. ${ }^{18-20}$ In this study, stability trends in the series of methyl-substituted 1,2dioxetanes could be rationalized by the effect of nonbonding repulsive interactions of the methyl substituents on the $\mathrm{O}-\mathrm{O}$ and $\mathrm{C}-\mathrm{C}$ bonds of the four-membered peroxide ring. Furthermore, trends in the chemiexcitation yields of this series could be understood on the basis of the merged mechanism and relative $\mathrm{C}-\mathrm{C}$ and $\mathrm{O}-\mathrm{O}$ bond strength, leading to the conclusion that a concerted, almost simultaneous, decomposition pathway would be responsible for highly efficient chemiexcitation (as observed in the case of tetramethyl-1,2-dioxetane), whereas, a biradical-like decomposition pathway would result in the formation of mainly ground state carbonyl products (as observed in the case of the unsubstituted 1,2-dioxetane). ${ }^{19}$

Twenty years after the publication of that work, we revisit - by means of quantum chemistry - the effect of the alkyl-substitution pattern on the stability of 1,2-dioxetanes. Thirty simple alkyl-substituted 1,2-dioxetane derivatives were selected and their geometry was optimized using semiempirical and DFT methods. The geometry of methyl-substituted derivatives was also optimized by ab initio methods. Results are compared with experimental activation parameters and a qualitative explanation for the stabilization effect of alkyl groups on the 1,2-dioxetane ring is proposed.

\section{Methods of Calculation}

Quantum chemical calculations. Initial geometries were submitted to full conformational search using molecular mechanics (MMFF94 force field) ${ }^{21}$ as implemented in the Spartan '02 package. The lowest energy conformers were optimized without constrains by means of 
semiempirical PM3 and AM1 methods and by using the density functional theory (DFT) at the Becke's three parameter hybrid functional, using the correlation functional of Lee, Yang, and Parr (B3LYP) level with the 6-31G(d) and 6-31+G(d,p) basis sets. ${ }^{22,23}$ Stationary points were confirmed as minima via vibrational frequency calculations. In order to calculate the cavity volume occupied by a dioxetane in a polar continuum, the COSMO model with B3LYP/6$31 \mathrm{G}(\mathrm{d})$ basis set was employed. ${ }^{24}$ The solvent cavity volumes thus obtained $\left(\mathrm{V}_{\mathrm{SC}}\right.$ in $\AA^{3}$ ) were converted into molar volumes $\left(\mathrm{V}_{\mathrm{M}}^{\mathrm{SC}}\right.$, in $\left.\mathrm{cm}^{3} \mathrm{~mol}^{-1}\right)$ by multiplying it by Avogadro's number and dividing by $10^{24}$. Ab initio calculations were performed by using the Gaussian 03 program package. ${ }^{25}$ Three-dimensional structures and surfaces were calculated by using the ArgusLab 4.0.1 software. $^{26}$ All calculations were performed at the advanced computing facilities (LCCA) of the University of São Paulo.

\section{Results and Discussion}

In order to investigate the effect of alkyl substituents on thermal stability of 1,2-dioxetane, thirty derivates were chosen, submitted to a full conformational analysis and their geometry optimized using the AM1, PM3 and B3LYP/6-31G(d) methods (Table 1). Semiempirical methods have been extensively used to investigate 1,2-dioxetanes thermal decompostion, ${ }^{16,17,27}$ whereas DFT B3LYP method provides accurate and reliable optimized structures with a lower computational cost when compared with MP2 calculations. ${ }^{28,29}$ Output parameters are given in Tables S1-S3 (All Tables cited as 'Table $\mathrm{S}$ ' is given in supplementary information).

Table 1. Structures of the 1,2-dioxetanes studied

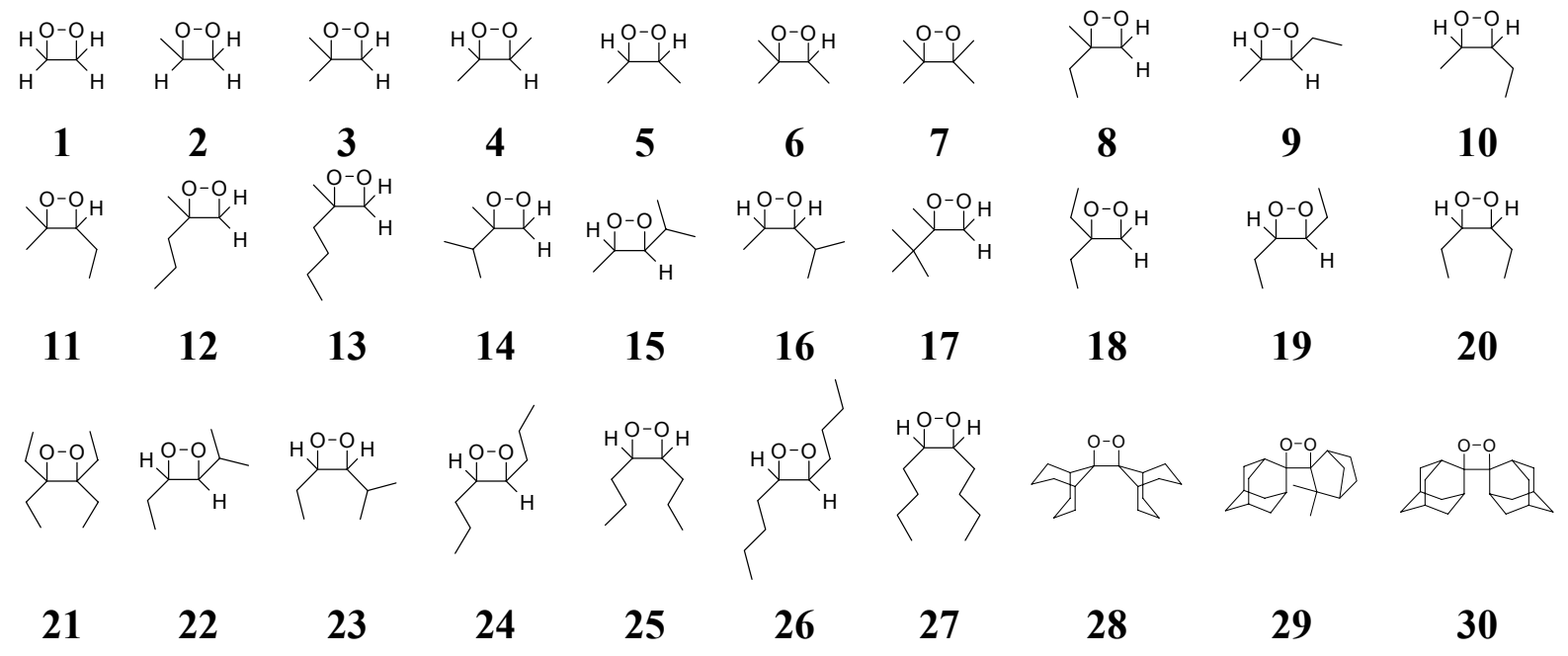

\section{Geometry optimization}

The determination of crystal structures of 1,2-dioxetanes by X-ray diffraction is difficult since most of these compounds are not crystalline, do not crystallize as single crystal or do not resist 
irradiation. ${ }^{3}$ However, from the available crystal structure data in the literature for six different 1,2-dioxetane derivatives, $\mathrm{d}(\mathrm{O}-\mathrm{O})$ (A list of all abbreviations and symbols employed is give before References) is systematically shorter than $\mathrm{d}(\mathrm{C}-\mathrm{C})$ (i.e., the ratio $\mathrm{d}(\mathrm{O}-\mathrm{O}) / \mathrm{d}(\mathrm{C}-\mathrm{C})<1$; Table S4). Both the semiempirical AM1 and DFT-B3LYP/6-31G(d) methods predict the same behavior for all derivatives, $\mathrm{d}(\mathrm{O}-\mathrm{O})$ is nearly constant whereas $\mathrm{d}(\mathrm{C}-\mathrm{C})$ is longer for more stable derivatives, i.e., the smallest $\mathrm{d}(\mathrm{O}-\mathrm{O}) / \mathrm{d}(\mathrm{C}-\mathrm{C})$ values are calculated for the tetrasubstituted derivates 7, 21, 28, 29, and 30 (Tables S1 and S3). However, the semiempirical PM3 method predicts the opposite tendency (i.e., $\mathrm{d}(\mathrm{O}-\mathrm{O}) / \mathrm{d}(\mathrm{C}-\mathrm{C})>1$ ) for almost all compounds in this study, except for the derivates $\mathbf{7}, \mathbf{2 1}, \mathbf{2 8}, \mathbf{2 9}$, and $\mathbf{3 0}$, which are the most puckered and stable ones (Table $\mathrm{S} 2)$. This method predicts that $\mathrm{d}(\mathrm{O}-\mathrm{O})$ becomes shorter for more stable derivatives $\mathbf{7}, \mathbf{2 1}, \mathbf{2 8}, \mathbf{2 9}$, and 30) whereas $d(C-C)$ becomes longer. This fact agrees with chemical intuition, but must be considered with caution. Figure 1 depicts the comparison between $d(\mathrm{O}-\mathrm{O}) / \mathrm{d}(\mathrm{C}-\mathrm{C})$ values calculated by AM1 and PM3, AM1 and B3LYP/6-31G(d), and PM3 and B3LYP/6-31G(d) methods. The linear regression coefficients obtained between AM1 and PM3 or B3LYP using all compounds are $r=0.988$ and $r=0.980$, respectively. If compounds 28, 29 and $\mathbf{3 0}$ (which are highly constrained) are excluded, the coefficients values are slightly reduced $(r=0.983$ and $r=$ 0.947 for PM3 and B3LYP, respectively) although visually the values for these dioxetanes do not appear to correlate well (Figure 1A and B). Furthermore, good linear correlation $(r=0.988)$ is also obtained between the values calculated by the PM3 and the more time-consuming B3LYP/6-31G(d) method for all compounds studied (Figure 1C).
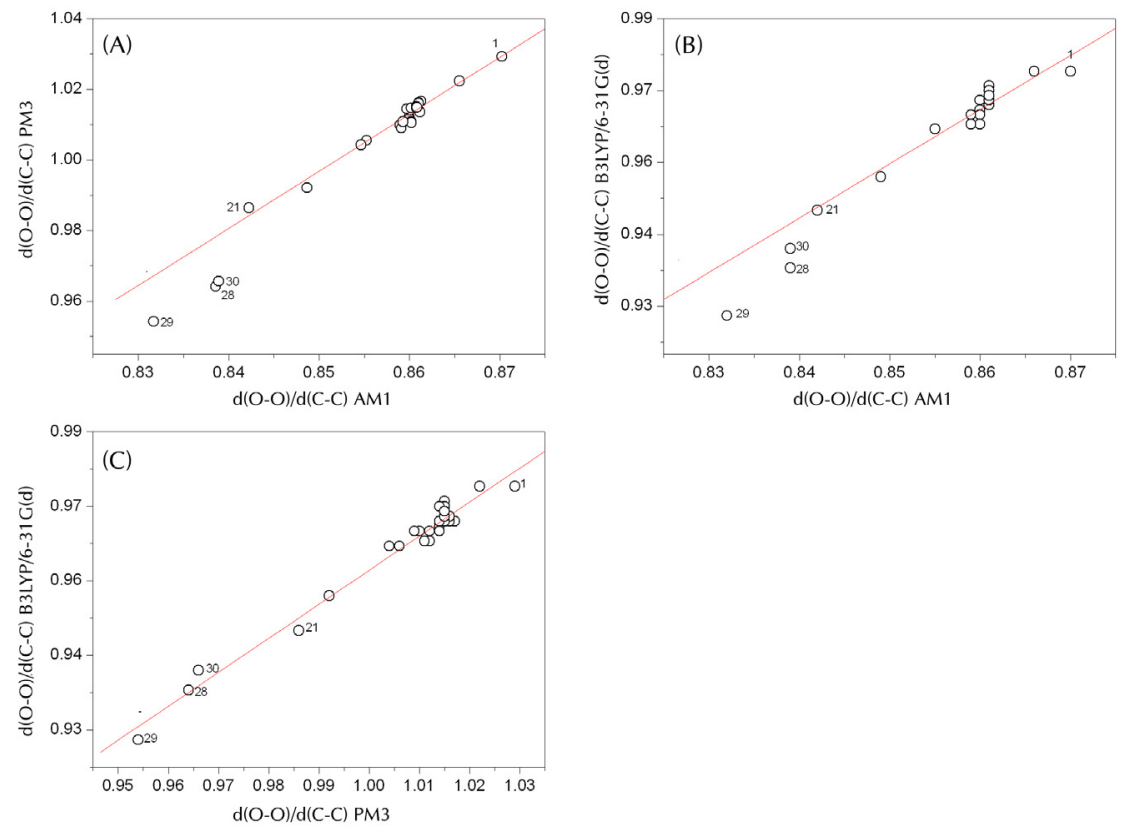

Figure 1. Comparison of $\mathrm{d}(\mathrm{O}-\mathrm{O}) / \mathrm{d}(\mathrm{C}-\mathrm{C})$ values calculated by: (A) AM1 and PM3 semiempirical methods, linear correlation calculated for 1 - 27; (B) AM1 and DFT-B3LYP/6-31G(d), linear correlation calculated for 1 - 27; (C) PM3 and DFT-B3LYP/6-31G(d), linear correlation calculated for $\mathbf{1}$ - 30. Numbers indicate some representative derivatives presented in Table 1. 
As expected, both bond distances calculated by means of the semiempirical PM3 and AM1 methods show excellent correlations. Interestingly, $\mathrm{d}(\mathrm{O}-\mathrm{O})$ calculated by means of DFT B3LYP method do not show good linear correlations with those calculated by the semiempirical methods, whereas $\mathrm{d}(\mathrm{C}-\mathrm{C})$ correlates very well (Table 2).

Table 2. Linear regression coefficients between structural data calculated by several theoretical methods for 1,2-dioxetanes $\mathbf{1}$ - $\mathbf{3 0}$

\begin{tabular}{ccccccc}
\hline & \multicolumn{3}{c}{ PM3 } & \multicolumn{3}{c}{ B3LYP $(6-31 \mathrm{G}(\mathrm{d}))$} \\
\hline & $\mathrm{d}(\mathrm{O}-\mathrm{O})$ & $\mathrm{d}(\mathrm{C}-\mathrm{C})$ & $\mathrm{d}(\mathrm{O}-\mathrm{O}) / \mathrm{d}(\mathrm{C}-\mathrm{C})$ & $\mathrm{d}(\mathrm{O}-\mathrm{O})$ & $\mathrm{d}(\mathrm{C}-\mathrm{C})$ & $\mathrm{d}(\mathrm{O}-\mathrm{O}) / \mathrm{d}(\mathrm{C}-\mathrm{C})$ \\
AM1 & $\mathbf{0 . 9 8 2 0}$ & $\mathbf{0 . 9 9 2 9}$ & $\mathbf{0 . 9 8 7 0}$ & 0.8393 & $\mathbf{0 . 9 8 3 6}$ & $\mathbf{0 . 9 7 9 9}$ \\
PM3 & & & & 0.8562 & $\mathbf{0 . 9 8 9 5}$ & $\mathbf{0 . 9 8 7 8}$ \\
\hline
\end{tabular}

It must be pointed out that theoretical studies on unimolecular decomposition of 1,2dioxetanes have been performed almost exclusively using the parent 1,2-dioxetane (1) and 3,3,4,4-tetramethyl-1,2-dioxetane (7) as model-compounds, because they require less computational efforts than more stable (and larger) 1,2-dioxetanes, as bisadamantylidene-1,2dioxetane (30). However, X-ray structural data of these simpler derivatives are not available and theoretical bond distances, angles and dihedral angles are very often compared with that of much more stable 1,2-dioxetanes (see Table S4). ${ }^{12-14,16,17,30}$ In other words, there are no experimental data concerning the structure of less stable 1,2-dioxetanes and, therefore, it is impossible to assign unequivocally the more adequate theoretical method to access the optimized geometry. In order to adequately compare structural parameters predicted by different methods with experimental values, the geometry of the derivative 30 was optimized by AM1, PM3, HF/6$31 \mathrm{G}(\mathrm{d})$ and B3LYP/6-31G(d) methods and the results evaluated with that obtained by X-ray diffraction (Table 3).

Table 3. Theoretical and X-ray structural parameters for the peroxidic ring of $\mathbf{3 0}^{\mathrm{a}}$

\begin{tabular}{lllll}
\hline & \multicolumn{4}{c}{} \\
& $\mathbf{d}(\mathbf{O}-\mathbf{O}), \mathbf{p m}$ & $\mathbf{d}(\mathbf{C}-\mathbf{C}), \mathbf{p m}$ & $\mathbf{d}(\mathbf{O}-\mathbf{O}) / \mathbf{d}(\mathbf{C}-\mathbf{C})$ & $\mathbf{\omega ,}^{\mathbf{0}}$ \\
\hline Experimental $^{31,32}$ & 148.0 & 154.9 & 0.955 & 21.3 \\
AM1 & $132.4(-10)$ & $157.8(1.9)$ & $0.839(-12)$ & $5.5(-74)$ \\
PM3 & $152.7(3.2)$ & $158.2(2.1)$ & $0.966(1.1)$ & $2.3(-89)$ \\
HF/6-31G(d) & $141.2(-4.6)$ & $156.9(1.3)$ & $0.899(-5.9)$ & $21.7(1.9)$ \\
B3LYP/6-31G(d) & $148.2(0.13)$ & $157.3(1.6)$ & $0.942(-1.4)$ & $22.2(4.2)$ \\
\hline
\end{tabular}

${ }^{a}$ Numbers in parenthesis indicate deviation from the experimental values, in percentage.

Calculated peroxide bond distances are in good agreement with the experimental values only for the B3LYP/6-31G(d) method. However, all methods predict d(C-C) which are only 2\% 
higher than the experimental value. One should notice that the peroxidic ring dihedral angles $(\angle \mathrm{COOC}, \omega)$ are not correctly predicted at all by AM1 as well as PM3 semiempirical methods. Both methods predict almost planar peroxidic rings $(\omega \sim 0)$ in complete disagreement with the experimental dihedral angle (Table 3). However, it should bee noticed that calculations of the $\mathrm{S}_{0}$ and the vertical $\mathrm{T}_{1}$ energies as a function of $\mathrm{d}(\mathrm{O}-\mathrm{O})$ by the semiempirical PM3 method have successfully reproduced the experimental activation energy for 1,2-dioxetane thermal decomposition. ${ }^{16,33}$ Interestingly, the $\mathrm{d}(\mathrm{O}-\mathrm{O}) / \mathrm{d}(\mathrm{C}-\mathrm{C})$ relation obtained by the PM3 method is in good agreement with the experimental data, although PM3 does not predict correctly $\mathrm{d}(\mathrm{O}-\mathrm{O})$ and $\omega$. If all parameters are considered it can be concluded that the B3LYP/6-31G(d) method is the most adequate one for the prediction of spiroadamantyl-1,2-dioxetane geometry (Table 3 ).

\section{Correlation of calculated geometry parameters and experimental free energies of activation} Experimental free energies of activation $\left(\Delta G^{\neq}\right)$for the decomposition of dioxetanes 1-30 are listed in Table S5 along with other activation parameters. Several linear correlations between the calculated structural parameters of 1,2-dioxetanes and their experimental $\Delta \mathrm{G}^{\neq}$were attempted. The following independent variables were chosen: molar volume from solvent exclude surface $\left(\mathrm{V}_{\mathrm{M}}\right)$, distance of the peroxidic bond $(\mathrm{d}(\mathrm{O}-\mathrm{O}))$, distance of the carbon-carbon bond in the 1,2dioxetane ring $(\mathrm{d}(\mathrm{C}-\mathrm{C}))$, dihedral angle $\omega$, dielectric constant in vacuo $(\mu)$, and $\mathrm{HOMO}$ and LUMO energies ( $\mathrm{E}_{\mathrm{HOMO}}$ and $\mathrm{E}_{\mathrm{LUMO}}$, respectively). Linear regression coefficients are shown in Tables 4.

Table 4. Linear regression coefficients (r) between several calculated independent variables and $\Delta \mathrm{G}^{\neq}$. a,b

\begin{tabular}{lccccccc}
\hline \multicolumn{1}{c}{ Method } & $\mathbf{V}_{\mathbf{M}}, \mathbf{~ c m}^{\mathbf{3}} \mathbf{m o l}^{\mathbf{1}}$ & $\mathbf{d}(\mathbf{O}-\mathbf{O}), \mathbf{p m}$ & $\mathbf{d}(\mathbf{C}-\mathbf{C}), \mathbf{p m}$ & \multicolumn{1}{c}{$\boldsymbol{\omega}^{\mathbf{0}}$} & $\mu, \mathbf{D}$ & $\mathbf{E}_{\text {HOMO }}, \mathbf{e V}$ & $\mathbf{E}_{\text {LUMO }}, \mathbf{e V}$ \\
\hline AM1 & 0.8849 & $\mathbf{- 0 . 9 6 3 4}$ & 0.9083 & -0.5913 & -0.7531 & $\mathbf{0 . 9 7 6 2}$ & 0.7673 \\
PM3 & 0.8849 & $\mathbf{- 0 . 9 8 3 2}$ & 0.9157 & -0.2298 & -0.5021 & $\mathbf{0 . 9 4 3 4}$ & $\mathbf{0 . 9 7 5 5}$ \\
B3LYP/6-31G(d) & 0.8848 & -0.8272 & $\mathbf{0 . 9 3 2 8}$ & 0.2958 & -0.8540 & 0.8341 & 0.5353 \\
\hline
\end{tabular}

${ }^{\mathrm{a}} \mathrm{r}>0.93$ were bold for clarity

${ }^{b}$ notice that positive $r$ values indicate proportional variation, whereas negative values indicate inverse correlation.

As previously assigned by Richardson, correlations with the $\Delta \mathrm{G}^{\neq}$values have the advantage that they are directly related to the experimental decomposition rate constants. ${ }^{12}$ Very good correlation between the $\mathrm{d}(\mathrm{O}-\mathrm{O})$, calculated by semiempirical methods, and $\Delta \mathrm{G}^{\neq}$is observed. The linear regression coefficient in this case is higher than those obtained for strain energy and $\omega$ by means of MM2 calculation $(0.715<\mathrm{r}<0.956) .{ }^{12}$ Contrarily, $\mathrm{d}(\mathrm{C}-\mathrm{C})$ calculated by B3LYP/6$31 \mathrm{G}(\mathrm{d})$ correlates better with the free energy of activation than $\mathrm{d}(\mathrm{O}-\mathrm{O})$.

Good correlations of both $\mathrm{E}_{\mathrm{HOMO}}$ and $\mathrm{E}_{\mathrm{LUMO}}$ are only obtained with the PM3 method, whereas AM1 data show good correlation only with $\mathrm{E}_{\text {HOMO }}$ and both orbital energies calculated 
by B3LYP/6-31G(d) method do not correlate linearly with $\Delta \mathrm{G}^{\neq}$. No appreciable linear correlation is observed for $\mathrm{V}_{\mathrm{M}}$ and $\mu$. Moreover and more important, the $\omega$ values calculated by any of the methods used do not show appreciable linear correlation with $\Delta \mathrm{G}^{\ddagger}$. These results conflict with those obtained by Richardson, who used force field parameterizations based on the experimental $\omega$ values for two dialkyl peroxides and two 1,2-dioxetanes in order to determine 1,2-dioxetanes dihedral angles theoretically by MM2 calculations. ${ }^{12}$ However, this correlation might be due mainly to the parameterization with the experimental X-ray data.

Activation parameters for the thermal decomposition of structurally different 1,2-dioxetanes have been reported by different research groups, which results in discrepant and not well comparable experimental data. In order to circumvent this problem, we have further optimized the geometry of compounds 1 - 7 (hereafter called 'methyl series') by means of HF/6-31G(d), $\mathrm{MP} 2 / 6-31 \mathrm{G}(\mathrm{d})$, and $\mathrm{B} 3 \mathrm{LYP} / 6-31+\mathrm{G}(\mathrm{d}, \mathrm{p})$ methods, since the activation parameters for the complete series of methyl-substituted 1,2-dioxetanes have been obtained by one research group. ${ }^{19,20}$ Output data are shown in Table S6-S8. Good linear correlation coefficients are obtained between the $\mathrm{d}(\mathrm{O}-\mathrm{O})$ as well as $\mathrm{d}(\mathrm{C}-\mathrm{C})$ calculated by semiempirical methods (i.e., AM1 and PM3) and $\Delta \mathrm{G}^{\neq}(\mathrm{r}>0.97$, Table 5). Carbon-carbon distances calculated by means of HartreeFock, MP2 and DFT methods, with the 6-31G(d) and 6-31+G(d,p) basis sets, also show very good linear correlation with the activation parameter $(\mathrm{r}>0.97)$, whereas very poor correlations are obtained on utilizing the $\mathrm{d}(\mathrm{O}-\mathrm{O})$. Interestingly, for the $\mathrm{MP} 2 / 6-31 \mathrm{G}(\mathrm{d})$ method a positive, although low $(\mathrm{r}=0.766)$, coefficient is obtained, whereas the coefficients for the HF and DFT methods are negative and still lower (Table 5).

Table 5. Linear regression coefficients (r) between several calculated independent variables and $\Delta \mathrm{G}^{\neq}$for the methyl series ${ }^{\mathrm{a}}$

\begin{tabular}{lcccccc}
\hline \multicolumn{1}{c}{ Method } & d(O-O), pm & $\mathbf{d}(\mathbf{C}-\mathbf{C}), \mathbf{p m}$ & $\mathbf{\omega}^{\mathbf{o}}$ & $\boldsymbol{\mu}, \mathbf{D}$ & $\mathbf{E}_{\text {HOMO }} \mathbf{e V}$ & $\mathbf{E}_{\mathbf{L U M O}}, \mathbf{e V}$ \\
\hline AM1 & $\mathbf{- 0 . 9 7 3 4}$ & $\mathbf{0 . 9 8 6 7}$ & 0.3663 & 0.8967 & $\mathbf{0 . 9 7 4 6}$ & -0.3569 \\
PM3 & $\mathbf{- 0 . 9 8 5 3}$ & $\mathbf{0 . 9 8 5 0}$ & -0.1322 & 0.8605 & -0.5377 & $\mathbf{0 . 9 7 5 1}$ \\
B3LYP/6-31G(d) & -0.3620 & $\mathbf{0 . 9 7 7 4}$ & -0.0571 & -0.4814 & 0.8931 & 0.9459 \\
HF/6-31G(d) & -0.3979 & $\mathbf{0 . 9 7 7 3}$ & 0.8464 & -0.9120 & 0.9323 & -0.6797 \\
MP2/6-31G(d) & 0.7658 & $\mathbf{0 . 9 8 9 4}$ & -0.1858 & -0.7189 & 0.9488 & 0.7739 \\
B3LYP/6-31+G(d,p) & -0.6660 & $\mathbf{0 . 9 7 6 0}$ & 0.7792 & -0.1178 & 0.8871 & 0.9480 \\
\hline
\end{tabular}

${ }^{\mathrm{a}} \mathrm{r}>0.95$ were set as bold for clarity.

Average standard deviation from linear regression analysis of the methyl series (d(C-C) vs. activation parameters) is $0.8 \mathrm{~kJ} \mathrm{~mol}^{-1}$ for $\Delta \mathrm{G}^{\neq}$(Table $\mathrm{S} 9$ ). Interestingly, within the methyl series, both $\mathrm{d}(\mathrm{C}-\mathrm{C})$ and $\mathrm{d}(\mathrm{O}-\mathrm{O})$ predicted by semiempirical methods show good correlation with activation parameters (Table 5). However, Adam and Baader have reported the activation parameters for cis/trans 3,4-dimethyl-1,2-dioxetanes and the cis isomer was found to be slightly more stable than the trans isomer. ${ }^{19}$ This result diverges from that reported for other $3,4-n$-alkyl- 
substituted symmetric derivatives (i.e., ethyl, propyl and butyl), whose trans isomers are more stable, but was confirmed later by Baumstark and collaborators. ${ }^{34,35}$ Unfortunately, none of the parameters calculated in this study indicate that the cis isomer is more stable than the trans-3,4dimethyl-1,2-dioxetane, pointing out the deficiency also of these rather sophisticated theoretical methods in predicting and rationalizing experimental stability trends for 1,2-dioxetanes.

As previously indicated, semiempirical methods predict that activation parameters are linearly correlated with both $\mathrm{d}(\mathrm{C}-\mathrm{C})$ and $\mathrm{d}(\mathrm{O}-\mathrm{O})$, but are not able to predict torsion angles in bisadamatylidene-1,2-dioxetane (Table 3). On the other hand, data obtained by ab initio and hybrid methods show good correlations only between the $\mathrm{d}(\mathrm{C}-\mathrm{C})$ and free activation energies, (Table 4) with the additional advantage that calculated dihedral angles are in considerable agreement with reported X-ray data (Table 3 and S4). The linear correlation coefficients for d(CC) obtained for the methyl series (Table 5) are considerably higher than those calculated for the whole series (1-30, Table 4), mainly due to the puckered compounds 28, 29 and 30. Linear regression coefficients between orbital energies and $\Delta \mathrm{G}^{\ddagger}$ higher than 0.95 are only observed for semiempirical methods. No appreciable linear correlation is observed for $V_{M}$ and $\mu$.

Since semiempirical methods cannot accurately predict $\omega$, and $\mathrm{d}(\mathrm{O}-\mathrm{O})$ calculated by ab intio and DFT methods do not show good correlation with $\Delta \mathrm{G}^{\neq}$, one may ask if there is a relation between $\mathrm{d}(\mathrm{O}-\mathrm{O})$ and $\omega$ that would explain the thermal stability of 1,2-dioxetanes. In this way, an attempt was made to obtain a factor able to model the empirical dependence between $\mathrm{d}(\mathrm{O}-\mathrm{O})$ and $\omega$. The $\omega$ value of the dioxetane ring for the unsubstituted 1,2-dioxetane 1 was forced to vary using the B3LYP/6-31G(d) method and the resulting $d(\mathrm{O}-\mathrm{O})$ determined. However, this approach proved to be unfruitful since changes in dihedral angles are compensated by variation in the distance of the $\mathrm{C}-\mathrm{O}$ bonds $(\mathrm{d}(\mathrm{C}-\mathrm{O}))$ and the $\mathrm{CCO}$ angles $(\theta)$. In other words, if a given variable was constrained $(\mathrm{d}(\mathrm{C}-\mathrm{O}) \mathrm{s}$ or $\theta \mathrm{s})$ the other changes, making it impossible to measure isolated effects.

Although we do not report calculations on the decomposition mechanism of 1,2-dioxetanes in this work, our theoretical calculations on the structure of these compounds can be utilized also to get some insight to the substituent influence on the decomposition mechanism. As noticed before, calculated $\mathrm{d}(\mathrm{C}-\mathrm{C})$ correlate well with the experimental $\Delta \mathrm{G}^{\neq}$values, however, in an 'inverse' manner (more stable derivatives show longer and therefore weaker C-C bonds). Whereas, with the exception of the PM3 method, theoretical structural data indicate that substituent influence on the $\mathrm{O}-\mathrm{O}$ bond distance is very low as can be seen from the almost constant $\mathrm{d}(\mathrm{O}-\mathrm{O})$ values for all derivatives studied (Tables $\mathrm{S} 1, \mathrm{~S} 3, \mathrm{~S} 6-\mathrm{S} 8$ ). This surprising fact may explain, at least partially, the lack of correlation between $\mathrm{d}(\mathrm{O}-\mathrm{O})$ and the experimental activation parameters (Tables 4 and 5). The trends observed for $\mathrm{d}(\mathrm{C}-\mathrm{C})$ confirm, now in a quantitative and general manner, the mechanistic interpretations made 20 years ago for the methyl series ${ }^{19}$, which were based on qualitative considerations with respect to the relative strength of the $\mathrm{C}-\mathrm{C}$ and $\mathrm{O}-\mathrm{O}$ bonds in the dioxetane ring. The larger and therefore weaker $\mathrm{C}-\mathrm{C}$ bond in stable, highly substituted 1,2-dioxetanes causes the decomposition mechanism of these derivatives to be more simultaneously concerted (synchronized $\mathrm{C}-\mathrm{C}$ and $\mathrm{O}-\mathrm{O}$ bond cleavage). 
Contrarily, the shorter and therefore stronger $\mathrm{C}-\mathrm{C}$ bond in unstable less substituted dioxetanes shifts the decomposition pathway to a biradical-like process (O-O bond cleavage much more advanced than $\mathrm{C}-\mathrm{C}$ bond cleavage). This conclusion, associated to the fact that higher stability is associated with higher excitation quantum yields for most derivatives (for specific exceptions see Scheme 2 and 3 as well as the associated discussion below), leads to the conclusion that efficient chemiexcitation should be associated to a concerted decomposition pathway, while, in biradicallike dioxetane decomposition excitation efficiency is low. This interpretation has already been given for the methyl series, but it appears from our structural calculations that it can be applied also to other 1,2-dioxetane derivatives. In other words, using the still controversial merged mechanism ${ }^{1,5,13,15}$, postulated thirty years ago by Waldemar Adam, ${ }^{18}$ and quantum chemical structural data it is possible to rationalize and may be also predict quantum yield trends for many 1,2-dioxetane derivatives.

\section{A qualitative model for the substituent influence on 1,2-dioxetane stability}

Another controversial point is the importance of the initial $\omega$ on thermal stability. ${ }^{1,36,37} \mathrm{CASSCF}$ and DDCI methods indicate that rotation about the $\mathrm{C}-\mathrm{C}$ bond, i.e., enlarging the $\omega$, is a fundamental variable in the mechanism of unimolecular 1,2-dioxetane decomposition. ${ }^{13,30}$ In order to clarify this point, we use here an empirical model for the qualitatively description of substituents effects on thermal stability of 1,2-dioxetanes. This model considers the influence of the position of the substituents (caused by steric interaction between 'bulky' substituents) on the structural parameters of the dioxetane ring. For simplicity, we consider only two directions: (i) up and down shift of substituents, which corresponds to a disrotatory movement around the zaxis, leading to an increase in $\mathrm{d}(\mathrm{C}-\mathrm{C})$ and a decrease in $\mathrm{d}(\mathrm{O}-\mathrm{O})$ (Scheme 1A). (ii) Front and back shift through the paper plan, which corresponds to a disrotatory movement around the $\mathrm{x}$ axis, leading to an increase in the dihedral angle $\omega$ and thereby to an increase in the O-O bond length without alteration of $\mathrm{d}(\mathrm{C}-\mathrm{C})$ (Scheme 1B).

(A)

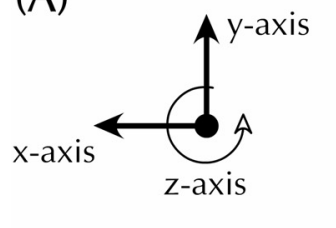

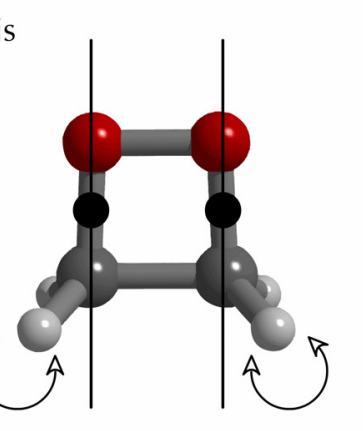

movement $i$

(B)
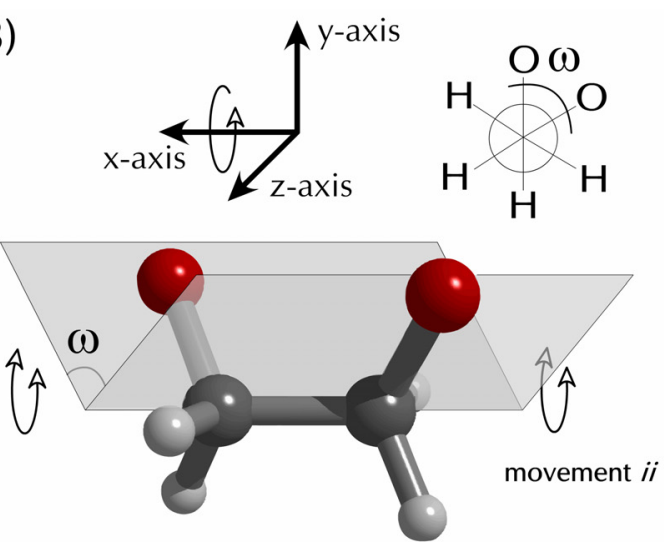

\section{Scheme 1}


We shall illustrate the validity of this approach using 3,3,4,4-tetraethyl-1,2-dioxetane (21), bisadamantylidene-1,2-dioxetane (30), dispirocyclohexyl-1,2-dioxetane (31) and 3,4-dimethylcyclohexyl-1,2-dioxetane (32). The structure of bisadamantylidene-1,2-dioxetane was constructed using experimental bond distances and angles (Table 3, Scheme 2A). As previous suggested by dreiding models, the $\alpha$-hydrogen atoms of both adamantly-substituents should suffer large nonbonding repulsion, which should best be relieved by movement $\boldsymbol{i i}$ leading to puckering the four membered ring. ${ }^{3}$ However, steric repulsion between more distant hydrogen atoms $(\beta-\mathrm{H})$ of the adamantly moieties should lead to steric compression of the peroxidic ring by movement $\boldsymbol{i}$, consequently increasing $\mathrm{d}(\mathrm{C}-\mathrm{C})$ and decreasing $\mathrm{d}(\mathrm{O}-\mathrm{O})$ (Scheme 2A). Similar effects are observed for $\mathbf{2 1}$ (Scheme 2B), however, in this case, a large number of conformational degrees of freedom is involved in order to relieve alkyl group repulsion and thus the peroxidic bond is compressed to a lower extent in $\mathbf{2 1}$ than in 30. In other words, $\alpha-\mathrm{H}$ repulsion (movement ii) is still an important factor whereas $\beta-\mathrm{H}$ interactions (movement i) are much less important in the most stable conformation of $\mathbf{2 1}$ (Scheme 2B).

Steric repulsion effects by $\beta-\mathrm{H}$ (movement $\boldsymbol{i}$ ) on the peroxidic ring of dioxetane 31 (Scheme $3 \mathrm{~A})$ are not observed whereas $\alpha-\mathrm{H}$ interaction (movement $i$ ) results in a slight increase of $\mathrm{d}(\mathrm{O}$ O) along with $\omega$ in agreement with the much lower stability of this derivative. On the other hand, if steric repulsion effects should occur in derivate 32, these should be much lower than even in $\mathbf{2 1}$, as there is no interaction possible between $\beta$-hydrogen atoms; movement $\boldsymbol{i}$ does not occur and substituent interaction not affect $\mathrm{d}(\mathrm{O}-\mathrm{O})$ and $\mathrm{d}(\mathrm{C}-\mathrm{C})$ notably. However, movement $\boldsymbol{i} i$ should be important, leading to an increase in the dihedral angle, reinforced considerably by the preferential chair conformation of the cyclohexane ring system. (Scheme 3B). This interpretation is in agreement with the experimentally observed $\Delta \mathrm{G}^{\neq}$of 1,2-dioxetane 32 and indicates that in this specific case the higher degree of puckering in the peroxidic ring may be responsible for its lower thermal stability.

However, it appears that the $\omega$ alone is not an important factor for dioxetane stability, since higher angles are the result of the combination of $\mathrm{x}$ - and z-axis rotation in order to access the more stable conformation of a given derivative. In the case of $\mathbf{3 0}$, the combination of steric compression (movement $\boldsymbol{i}$ ) and twisting due to nonbonding $\alpha$-hydrogen atom interactions (movement $\mathrm{ii}$ ) leads to the experimentally determined dihedral angle of $21.3^{\circ}$, however this dioxetane is extremely stable as further rotation around the $\mathrm{C}-\mathrm{C}$ bond is avoided by $\alpha$-hydrogen atom interactions. This effect is reduced systematically on going to the derivatives $\mathbf{2 1}, \mathbf{3 1}$ and $\mathbf{3 2}$, consequently, spirodicyclohexyl-1,2-dioxetane is more likely to rotate over the $\mathrm{C}$-C bond than bisadamantylidene-1,2-dioxetane and is therefore less stable. 


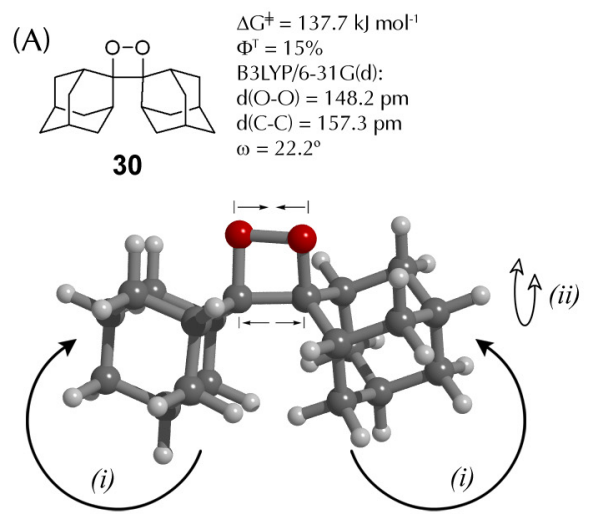

(B)
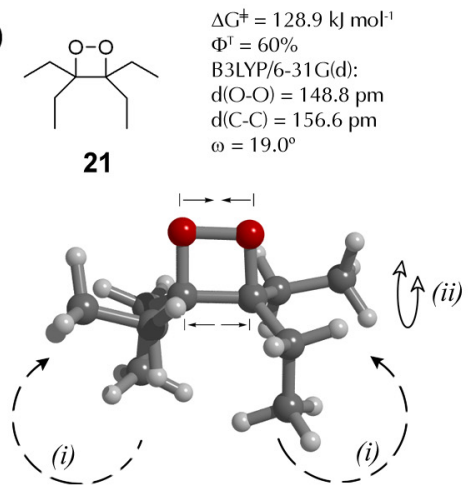

\section{Scheme 2}

This approach can also be utilized in a tentative to rationalize the triplet quantum yields obtained in the thermal decomposition of dioxetanes 21, 30, 31, 32 and 33, specifically the much lower yields observed for 33 (Schemes 2 and 3). It should be mentioned here that a general explication for quantum yield trends in dioxetane decomposition has never been given, neither in experimental work nor in any theoretical approach. ${ }^{1,3-7}$ The only tendency observed experimentally is that more stable dioxetanes possess higher quantum yields. ${ }^{4,19,38,39}$ In a theoretical approach Tanaka and Tanaka conclude that C-C-bond rotation is necessary for efficient excited state formation. ${ }^{14}$ However, no attempt has been made up to now to correlate quantum yields and structural data using this approach. If one considers that $\mathrm{C}$-C-bond rotation is necessary for efficient excited state formation, this is only possible in the case of the bisadamantyl-substituted 1,2-dioxetane 30 if $\mathrm{C}-\mathrm{C}$ bond cleavage accompanies the $\mathrm{O}-\mathrm{O}$ bond cleavage ('merged' mechanism) in order to minimize $\alpha$-hydrogen interaction between the two adamantly-substituents. The high quantum yields observed for the decomposition of this dioxetane corroborate with the occurrence of the merged mechanism in its decomposition and the still higher yields obtained for the tetraethyl derivative $\mathbf{2 1}$ as well as $\mathbf{3 1}$ and $\mathbf{3 2}$ might be understood by the greater facility for rotation of these derivatives as compared to $\mathbf{3 0}$ (Schemes 2 and 3). Furthermore, and more importantly, the considerably lower yields $\left(\Phi^{T}=1 \%\right)^{40,41}$ observed in the decomposition of the tricyclic 1,2-dioxetane 33 (Scheme 3C) might be rationalized by the impossibility of $\mathrm{C}$-C-bond rotation in this derivative, even when this bond is considerably elongated, due to conformational restrictions introduced by the two condensed cyclohexyl rings. Additionally, this derivative shows very low thermal stability even so its peroxidic ring shows small dihedral angle $\left(\omega \sim 8^{\circ}\right)$, indicating again that the dihedral angle alone is not an indicative for stability and also showing that dioxetane decomposition must not necessarily proceed by $\mathrm{C}$-C-bond rotation, however this movement might be necessary for efficient excited state formation. 
(A)
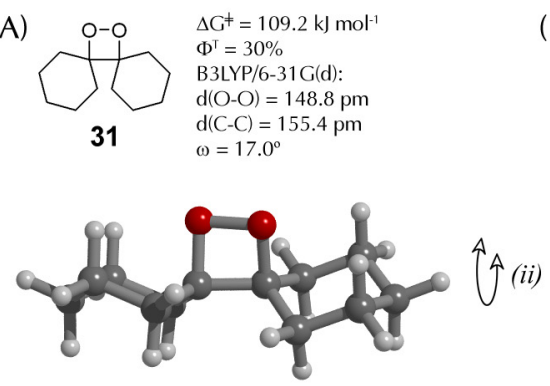

(B)
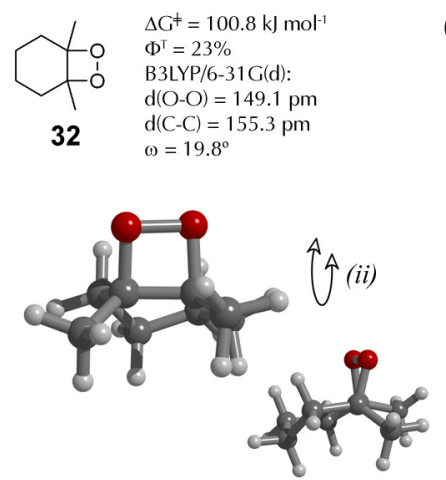

(C)
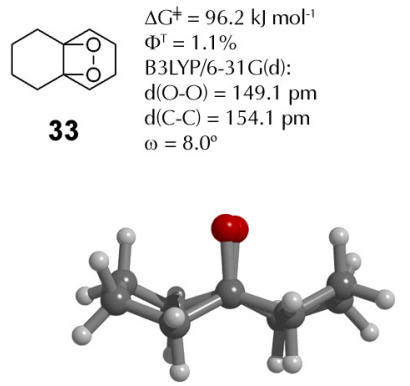

\section{Scheme 3}

A final comment on 3,3-substituited derivatives is appropriate since the stabilization effect caused by two geminal substituents cannot be easily explained by this model, even if one considers the Thorpe-Ingold effect. ${ }^{42,43}$ The following data are of interest: ${ }^{34}$ 3,3-dimethyl, 3-methyl-3-ethyl, 3-methyl-3-n-propyl, and 3-methyl-3-n-butyl-1,2-dioxetane have free activation energies of $c a .100 \mathrm{~kJ} \mathrm{~mol}^{-1}$, this value is slightly increased for 3-methyl-3-i-propyl (102 kJ mol ${ }^{-1}$ ), 3-methyl-3-t-butyl (104 kJ mol$\left.{ }^{-1}\right)$, and 3,3-diethyl-1,2-dioxetane (103 $\left.\mathrm{kJ} \mathrm{mol}^{-1}\right)$ (Table S5). A considerable increase in thermal stability is only observable for the di-isopropyl substituted derivative 34 (Scheme 4, $113 \mathrm{~kJ} \mathrm{~mol}^{-1}$ ), which shows a higher free energy of activation value than the tetrasubstituted 1,2-dioxetane $7\left(108 \mathrm{~kJ} \mathrm{~mol}^{-1}\right.$, Table S5).

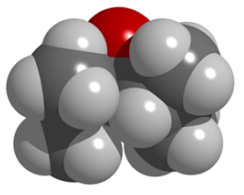

A
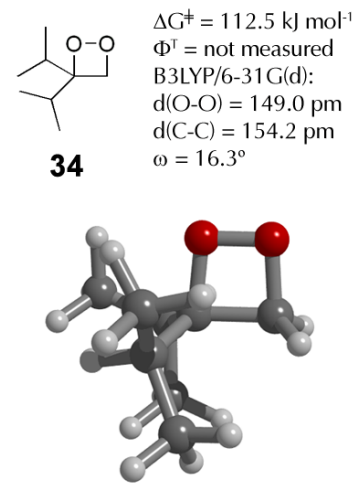

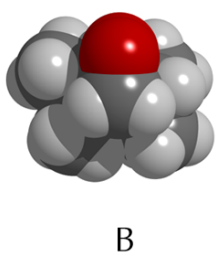

B

\section{Scheme 4}

On the basis of the fact that no significant 3,3-substituent effect is observed in alkylsubstituted dioxetane, except for the di- $i$-propyl derivative, we decide to optimize the geometry of its lowest energy conformer by means of B3LYP/6-31G(d), given that this method has proved to be adequate to describe $\omega$. The theoretical output predicts $\omega=16.3^{\circ}$ and therefore a completely puckered structure (Scheme 4). Both isopropyl groups are constrained by the two hydrogen atoms bonded to C4 (Scheme 4, view A) and by themselves (Scheme 4, view B). Although, steric hindrance caused by hydrogen atoms is very small, in this case a combination of 
rotational restrictions $(\mathrm{iPr} / \mathrm{iPr}, \mathrm{Pr} / \mathrm{H} 4$, and $\mathrm{iPr} / \mathrm{H} 4)$ appears to be responsible for the stabilization effect of $c a .10 \mathrm{~kJ} \mathrm{~mol}^{-1}$ in this dioxetane as compared to other 3,3-disubstituted derivatives.

\section{Conclusions}

The following conclusions are obtained in this work:

1. Since the semiempirical PM3 and AM1 methods do not adequately describe dihedral angles for bisadamantylidene-1,2-dioxetane (30), it is questionable if they are able to accurately predict $\omega$ for less stable derivatives, e.g., parent 1,2-dioxetane or tetramethyldioxetane. In this context, it should be considered that AM1 and PM3 methods are both based on the Neglect of Differential Diatomic Overlap (NDDO) integral approximation, but with an automatic parameterization procedure for PM3. ${ }^{44}$ These methods were designed to reproduce heats of formation and structures of a large number of organic molecules. However, their use for geometry optimization of small rings and molecules with neighboring lone-pair to lone-pair interactions is still controversial. $^{45}$

2. Among the methods used in this work, the hybrid DFT B3LYP/6-31G(d) method appears to be the most adequate for structural calculations on 1,2-dioxetanes as it is able to correctly predict the structure of the adamantly-substituted dioxetane 30. However, it should be mentioned that the adequateness of DFT methods to access the properties of unoccupied orbitals is still matter of discussion in the literature. ${ }^{46}$

3. Good linear correlation with negative coefficients are obtained between the O-O-bond distances calculated by AM1 and PM3 and experimental activation parameters (more stable dioxetanes show shorter O-O bonds), however, it might be suspected that these could be due to artifacts caused by the lack of theses methods to predict dihedral angles.

4. C-C-bond distances, calculated by any of the methods used show very good correlation with experimental dioxetane stability data leading to positive coefficients (more stable dioxetanes show longer C-C bonds).

5. Dihedral angles, as well as other calculated parameters, do not lead to satisfactory linear correlations with activation parameters.

6. High level quantum chemistry calculations on the series of methyl-substituted 1,2-dioxetanes also show good linear correlations only between $\Delta \mathrm{G}^{\ddagger}$ and d(C-C).

7. The substituent effect on dioxetane structure and stability is rationalized using a qualitative model based on the steric interaction between substituents. This model is utilized to explain stability trends in some highly substituted 1,2-dioxetanes. The qualitative predictions made using this model are confirmed by theoretical structural parameters. The model is also used to explain tendencies in the triplet excitation yields of this series of 1,2-dioxetanes.

8. The calculated relative values for $\mathrm{C}-\mathrm{C}$ and $\mathrm{O}-\mathrm{O}-$ bond distances, combined with experimental excitation quantum yields, allow to postulate that concerted 1,2-dioxetane decomposition should be associated to high chemiexcitation efficiency. 


\section{Abbreviations and Symbols}

$\begin{array}{ll}\mathrm{d}(\mathrm{O}-\mathrm{O}): & \text { distance of the peroxidic bond, formed by } \mathrm{O} 1 \text { and } \mathrm{O} 2 . \\ \mathrm{d}(\mathrm{C}-\mathrm{C}): & \text { distance of the carbon-carbon bond, formed by } \mathrm{C} 3 \text { and } \mathrm{C} 4 . \\ \mathrm{d}(\mathrm{C}-\mathrm{O}): & \text { distance of the carbon-oxigen bond, formed by } \mathrm{C} 3 \text { and } \mathrm{O} 2 \text { or } \mathrm{C} 4 \text { and } \mathrm{O} 1 . \\ \mathrm{d}(\mathrm{O}-\mathrm{O} / \mathrm{d}(\mathrm{C}-\mathrm{C}): & \text { ratio between } \mathrm{d}(\mathrm{O}-\mathrm{O}) \text { and } \mathrm{d}(\mathrm{C}-\mathrm{C}) . \\ \mathrm{V}_{\mathrm{M}}: & \text { molar volume calculated from solvent exclusion surface. } \\ \omega, \angle(\mathrm{COOC}): & \text { dihedral angle between } \mathrm{C} 3-\mathrm{O} 1-\mathrm{O} 2-\mathrm{C} 4 . \\ \theta, \angle(\mathrm{CCO}): & \text { angle between } \mathrm{C} 4-\mathrm{C} 3-\mathrm{O} 2 \text { or } \mathrm{C} 3-\mathrm{C} 4-\mathrm{O} 1 . \\ \mu: & \text { dielectric constant. }\end{array}$

\section{Acknowledgements}

We thank the Laboratory of Advanced Scientific Computation of the University of São Paulo LCCA for making the programs and computation facilities available to us. This work was supported by Fundação de Amparo à Pesquisa no Estado de São Paulo - FAPESP, Conselho Nacional de Desenvolvimento Científico e Tecnológico - CNPq, Coordenação de Aperfeiçoamento de Pessoal de Nível Superior - CAPES and Programa de Apoio ao Desenvolvimento Científico e Tecnológico - PADCT.

\section{References}

1. Baader, W. J.; Stevani, C. V.; Bastos, E. L. In The chemistry of peroxides; Rappoport, Z., Ed.; Wiley: Chichester, 2006; Vol. 2, pp 1211-1278.

2. Carpenter, B. K. Chem. Soc. Rev. 2006, 35, 736-747.

3. Adam, W. In The chemistry of peroxides; Patai, S., Ed.; Wiley: Chichester, 1983, pp 829920.

4. Adam, W.; Cilento, G. Chemical and biological generation of excited states; Academic Press: New York, 1982.

5. Adam, W.; Cilento, G. Angew. Chem., Int. Ed. Engl. 1983, 22, 529-542.

6. Adam, W.; Heil, M.; Mosandl, T.; Saha-Moeller, C. R. In Organic Peroxides; Ando, W., Ed.; Wiley: Chichester, 1992, pp 221-254.

7. Adam, W.; Trofimov, A. V. In The chemistry of peroxides; Rappoport, Z., Ed.; Wiley: Chichester, 2006; Vol. 2, pp 1171-1209.

8. Adam, W.; Encarnacion, L. A. A.; Zinner, K. Chem. Ber.-Recl. 1983, 116, 839-846.

9. Schaap, A. P.; Handley, R. S.; Giri, B. P. Tetrahedron Lett. 1987, 28, 935-938.

10. Schaap, A. P.; Chen, T. S.; Handley, R. S.; Desilva, R.; Giri, B. P. Tetrahedron Lett. 1987, 28, 1155-1158. 
11. Schaap, A. P.; Sandison, M. D.; Handley, R. S. Tetrahedron Lett. 1987, 28, 1159-1162.

12. Richardson, W. H. J. Org. Chem. 1989, 54, 4677-4684.

13. Wilsey, S.; Bernardi, F.; Olivucci, M.; Robb, M. A.; Murphy, S.; Adam, W. J. Phys. Chem. A 1999, 103, 1669-1677.

14. Tanaka, C.; Tanaka, J. J. Phys. Chem. A 2000, 104, 2078-2090.

15. Wilson, T. Photochem. Photobiol. 1995, 62, 601-606.

16. Wilson, T.; Halpern, A. M. J. Phys. Org. Chem. 1995, 8, 359-363.

17. Vasil'ev, R. F. High Energy Chem. 2002, 36, 170-178.

18. Adam, W. Adv. Heterocycl. Chem. 1977, 21, 437.

19. Adam, W.; Baader, W. J. J. Am. Chem. Soc. 1985, 107, 410-416.

20. Adam, W.; Baader, W. J. Angew. Chem., Int. Ed. 1984, 23, 166-167.

21. Halgren, T. J. Am. Chem. Soc. 1990, 112, 4710-4723.

22. Lee, C.; Yang, W.; Parr, R. G. Phys. Rev. B: Condens. Matter 1988, 37, 785-789.

23. Becke, A. D. J. Chem. Phys. 1993, 98, 5648-5652.

24. Klamt, A.; Schüürmann, G. J. Chem. Soc., Perkin Trans. 2 1993, 799.

25. Frisch, M. J.; Trucks, G. W.; Schlegel, H. B.; Scuseria, G. E.; Robb, M. A.; Cheeseman, J. R.; Montgomery, J., J. A.; Vreven, T.; Kudin, K. N.; Burant, J. C.; Millam, J. M.; Iyengar, S. S.; Tomasi, J.; Barone, V.; Mennucci, B.; Cossi, M.; Scalmani, G.; Rega, N.; Petersson, G. A.; Nakatsuji, H.; Hada, M.; Ehara, M.; Toyota, K.; Fukuda, R.; Hasegawa, J.; Ishida, M.; Nakajima, T.; Honda, Y.; Kitao, O.; Nakai, H.; Klene, M.; Li, X.; Knox, J. E.; Hratchian, H. P.; Cross, J. B.; Bakken, V.; Adamo, C.; Jaramillo, J.; Gomperts, R.; Stratmann, R. E.; Yazyev, O.; Austin, A. J.; Cammi, R.; Pomelli, C.; Ochterski, J. W.; Ayala, P. Y.; Morokuma, K.; Voth, G. A.; Salvador, P.; Dannenberg, J. J.; Zakrzewski, V. G.; Dapprich, S.; Daniels, A. D.; Strain, M. C.; Farkas, O.; Malick, D. K.; Rabuck, A. D.; Raghavachari, K.; Foresman, J. B.; Ortiz, J. V.; Cui, Q.; Baboul, A. G.; Clifford, S.; Cioslowski, J.; Stefanov, B. B.; Liu, G.; Liashenko, A.; Piskorz, P.; Komaromi, I.; Martin, R. L.; Fox, D. J.; Keith, T.; Al-Laham, M. A.; Peng, C. Y.; Nanayakkara, A.; Challacombe, M.; Gill, P. M. W.; Johnson, B.; Chen, W.; Wong, M. W.; Gonzalez, C.; Pople, J. A.; Gaussian, Inc.: Wallingford CT, 2004.

26. Thompson, M. A.; 4.0.1 ed.; Planaria Software LLC: Seattle, 2005.

27. Eaker, C. W.; Juergen, H. Theor. Chim. Acta 1975, 40, 113-118.

28. Neugebauer, A.; Haefelinger, G. THEOCHEM 2002, 585, 35-47.

29. Jensen, F. Introduction to Computational Chemistry; 2nd Edition ed.; John Wiley \& Sons: Chichester, 2006.

30. Rodriguez, E.; Reguero, M. J. Phys. Chem. A 2002, 106, 504-509.

31. Hess, J.; Vos, A. Acta Crystallogr. Sect. B-Struct. Commun. 1977, 33, 3527-3530.

32. Numan, H.; Wieringa, J. H.; Wynberg, H.; Hess, J.; Vos, A. J. Chem. Soc., Chem. Commun. 1977, 591-592.

33. Clark, T. In Recent experimental and computational advances in molecular spectroscopy; Fausto, R., Hollas, J. M., Eds.; Kluwer Academic: Dordrecht, 1993, pp 369-380. 
34. Baumstark, A. L. In Advances in Oxygenated Processes; Padwa, A., Ed.; Jai Press Inc.: Greenwhich, 1988; Vol. 1, pp 31-84.

35. Baumstark, A. L.; Retter, C. A.; Tehrani, K.; Kellogg, C. J. Org. Chem. 1987, 52, 33083311.

36. Schuster, G. B.; Turro, N. J.; Steinmetzer, H. C.; Schaap, A. P.; Faler, G.; Adam, W.; Liu, J. C. J. Am. Chem. Soc. 1975, 97, 7110-7118.

37. Pichierri, F. THEOCHEM 2004, 668, 179-187.

38. Bechara, E. J. H.; Baumstark, A. L.; Wilson, T. J. Am. Chem. Soc. 1976, 98, 4648-4649.

39. Bechara, E. J. H.; Wilson, T. J. Org. Chem. 1980, 45, 5261-5268.

40. Kopecky, K. R.; Filby, J. E. Can. J. Chem. 1979, 57, 283-288.

41. Kopecky, K. R.; Lockwood, P. A.; Gomez, R. R.; Ding, J. Y. Can. J. Chem. 1981, 59, 851858.

42. Ingold, C. K. J. Chem. Soc., Chem. Commun. 1921, 1921, 305.

43. Beesley, R. M.; Ingold, C. K.; Thorpe, J. F. J. Chem. Soc., Chem. Commun. 1915, 107, 10801106.

44. Stewart, J. J. P. J. Comput. Chem. 1989, 10, 221.

45. Stewart, J. J. P. J. Comput.-Aided Mol. Des. 1990, 4, 1-105.

46. Fulde, P. Electron correlations in molecules and solids; Springer-Verlag: Berlin, 1995; Vol. 100. 